\title{
Detección de restricciones en la producción de agave azul (Agave tequilana Weber var. azul) mediante percepción remota
}

\author{
Detection of restrictions on production of blue agave \\ (Agave tequilana Weber var. blue) using remote sensing
}

\section{Ramón Ceja Ramírez ${ }^{1}$, Diego Raymundo González Eguiarte ${ }^{1 \ddagger}$, José Ariel Ruiz Corral ${ }^{2}$, Luis Alberto Rendón Salcido ${ }^{1}$ y José Germán Flores Garnica ${ }^{2}$}

\footnotetext{
${ }^{1}$ Centro Universitario de Ciencias Biológicas y Agropecuarias (CUCBA) de la Universidad de Guadalajara. Km 15.5 Carretera a Nogales, Predio Las Agujas. 45110 Zapopan, Jalisco, México.

*Autor responsable (diegonz@cucba.udg.mx)

${ }^{2}$ INIFAP-CIRPAC. Parque de Los Colomos s/n Col. Providencia. 44660 Guadalajara, Jalisco, México.
}

\section{RESUMEN}

El agave azul (Agave tequilana Weber, var. azul) se utiliza, principalmente, para la producción del Tequila; una bebida espirituosa. El estado de Jalisco, México, contribuye con el $90 \%$ de la producción; esto constituye un importante apoyo a la economía del Estado. El objetivo de la presente investigación fue determinar la superficie ocupada por agave azul, que presentó restricciones en su producción en la región Valles, correspondiente a los municipios de Tequila, Amatitán y El Arenal, en el estado de Jalisco, México, por medio de percepción remota. Se utilizó una imagen adquirida por el satélite LANDSAT 5 el 2 de abril de 2011, la cual se procesó para su calibración radiométrica, corrección atmosférica y georreferenciación. La interpretación digital se hizo a través del proceso de clasificación supervisada utilizando la opción de máxima probabilidad. Los campos de entrenamiento se seleccionaron de información de campo y de la base de datos del Consejo Regulador del Tequila (CRT). Los resultados se plasmaron en mapas temáticos; distribución de agave y no agave y distribución de agave con restricciones. El 45\% del área ocupada por el cultivo presentó restricciones relacionadas con: aspectos económicos (restricción tipo 1), plagas y enfermedades (restricción tipo 2) y efectos por exceso de humedad del suelo (restricción tipo 3). Para evaluar la precisión de estos datos se aplicó una matriz de error que reportó una precisión general del $73 \%$. Este valor es aceptable considerando la resolución a $30 \mathrm{~m}$ del sensor (LANDSAT 5) y la peculiaridad del cultivo. El uso de imágenes LANDSAT por su resolución espectral y radiométrica es aceptable para el estudio del

Cita recomendada:

Ceja Ramírez, R., D. R. González Eguiarte, J. A. Ruiz Corral, L. A. Rendón Salcido y J. G. Flores Garnica. Detección de restricciones en la producción de agave azul (Agave tequilana Weber var. azul) mediante percepción remota. Terra Latinoamericana 35: 259-268. cultivo del agave azul según lo observado en campo y lo expresado por el procesamiento de la imagen.

Palabras clave: landsat, clasificación supervisada, tequila.

\section{SUMMARY}

The blue agave (Agave tequilana Weber, blue var.) is mainly used for the production of tequila, an alcoholic beverage. The state of Jalisco, Mexico, contributes $90 \%$ of the domestic tequila production, which makes up an important part of the state's economy. The aim of this research was to determine the area occupied by blue agave showing restrictions in plant development. The study area includes the municipalities of Tequila, Amatitan and El Arenal, Jalisco, Mexico. For this purpose, the image from April $2^{\text {nd }}, 2011$, taken by the Landsat 5 satellite was used. Digital interpretation was done through the process of supervised classification using the maximum likelihood option. The results are shown in thematic maps; distribution of areas occupied and not occupied with agave and distribution of agave affected by restrictions. Finally, a table with the covers registered and their areas shows that $45 \%$ of the area occupied by agave has some type of restriction. To assess the accuracy of these data, an error matrix reported an overall accuracy of $73 \%$. This value is acceptable considering the resolution at $30 \mathrm{~m}$ of the sensor (LANDSAT 5) and the peculiarity of the crop. The use of LANDSAT images for their spectral and radiometric resolution is acceptable for the study of blue agave culture as observed in the field and expressed by image processing.

Recibido: febrero de 2017. Aceptado: junio de 2017. Publicado en Terra Latinoamericana 35: 259-268. 
Index words: landsat, supervised classification, tequila.

\section{INTRODUCCIÓN}

El agave azul (Agave tequilana Weber, var. azul) se utiliza, principalmente, para la producción del Tequila, una bebida espirituosa (Bautista-Justo et al., 2001); y recientemente para la producción de miel de agave e inulina. En México, el agave azul se cultiva en la región conocida como Denominación de Origen del Tequila (DOT) reconocimiento que otorgó la Unión Europea a México en 1997 y que comprende a los estados de Jalisco (126 municipios), Michoacán (30 municipios), Tamaulipas (11 municipios), Nayarit (8 municipios) y Guanajuato (7 municipios), contribuyendo Jalisco con el 90\% de la producción (González et al., 2007).

Desde finales deladécada de los $90 \mathrm{~s}$, las plantaciones de agave han presentado problemas debido a factores que restringen el desarrollo normal de la planta. En los primeros años de la década pasada, a través del Consejo Regulador del Tequila, instituciones de investigación, enseñanza y productores, desarrollaron trabajos para determinar las causas del problema, enfocándose a enfermedades y plagas; entre los más estudiados están el daño por el picudo del agave (Scyphophorus acupunctatus) y la marchitez del agave atribuida a la bacteria Erwinia caratovora (González et al., 2007).

Una restricción es un factor o grupo de factores que afectan negativamente el desarrollo de un organismo; por ejemplo, la luz solar como forma de radiación electromagnética influye en procesos fisiológicos de plantas y animales (Valladares, 2004). Al considerar una restricción como factor negativo en el desarrollo de la planta que impide su manifestación como planta vigorosa, y al estar afectada la plantación por algún tipo de restricción, ésta se manifiesta físicamente con características que el observador puede distinguir a simple vista.

En la presente investigación, se usó el concepto restricción, según Bozinovic y Canals (2009) en el sentido de limitación. Es decir, según estos autores, "ningún organismo puede hacer de todo pues está limitado por sus genes, su historia, sus características biofísicas y mecánicas, su fisiología y conducta, estilo de vida y por el ambiente. En este sentido existirán restricciones internas (históricas) y externas (ecológicas). Dentro de estas restricciones existirán compromisos y plasticidad que dictarán el conjunto posible de características".

Las tecnologías de información geográfica (TIG), incluyen a la percepción remota, que actualmente utiliza imágenes de satélite multiespectrales que se aplican para estimar tipos de cubiertas sobre la superficie terrestre y la condición de las mismas (Lencinas y Mohr-Bell, 2007). De esta manera, se puede aplicar esta tecnología para identificar las superficies con plantaciones de agave, diferenciar sus condiciones de desarrollo y discriminar aquellas superficies cuyas características en la imagen sugieran alguna restricción.

Flores et al. (2008), mencionan que para el agave existen estudios concernientes a su fisiología, enfermedades y condiciones ambientales, más no hay estudios documentados en el uso de tecnología de satélite para su localización. El Consejo Regulador del Tequila, presenta un artículo titulado "El Agave Azul a través de la Imagen de Satélite" ("Blue Agave Through a Satellite Image") donde se puede visualizar la metodología para cuantificar predios con plantaciones de agave (CRT, 2004). Los trabajos publicados con respecto a este cultivo están enfocados a producción de tequila, aspectos ambientales, de manejo, de la composición propia del vegetal o de la organización para la producción, y en el caso de la aplicación de tecnología satelital se refieren a cultivos "comunes" (Manjarrez-Domínguez et al., 2007; Lencinas y MohrBell, 2007; Vega et al., 2008).

Dado que cualquier fenómeno que ocurra sobre la superficie de la tierra: vegetación, cultivos, cuerpos de agua, suelos etc. se puede detectar y analizar mediante la tecnología de la percepción remota (González, 2004), es factible inferir la manifestación de la "salud" del cultivo o de su condición de desarrollo a través de la interpretación de imágenes de satélite.

Una imagen de satélite es un arreglo de columnas y renglones que conforman una matriz de datos numéricos que representan la intensidad de la energía electromagnética reflejada o emitida por los objetos en la superficie de la tierra (Jensen, 2005; Smith, 2012). Las imágenes se pueden registrar en bandas individuales del espectro electromagnético, como ocurre en los satélites del programa LANDSAT; es decir, la misma escena capturada en diferentes bandas; Banda 1, Banda 2, Banda 3, etc., que en conjunto conforman una imagen multiespectral. Estas imágenes son adquiridas transformando la energía recibida por el sensor a 
valores de 8 bits; el pixel toma un valor de 0 a 255 , dependiendo de la energía reflejada por los objetos. Estos valores, que se conocen como números digitales (ND), son los datos originales (Chuvieco, 1995). Las imágenes del programa de satélites LANDSAT son consideradas como de resolución media con un tamaño de pixel de $30 \mathrm{~m}$ en multiespectral y $120 \mathrm{~m}$ en infrarrojo térmico (Smith, 2012).

Se utilizó la imagen del satélite LANDSAT 5 adquirida el 2 de abril del año 2011; a la cual se le realizaron los procesos de calibración radiométrica, corrección atmosférica y georreferenciación.

El análisis con fines de obtener información se puede hacer mediante procesos digitales aplicando las estadísticas de la imagen (clasificación supervisada, clasificación no supervisada) o mediante el análisis visual a través de un compuesto a color (Lillesand y Kieffer, 1987; López y Caselles, 1991; López et al., 2008).

El objetivo de la presente investigación fue identificar a través de la imagen LANDSAT 5, la superficie con plantaciones de agave, la presencia de agave con restricciones en su desarrollo, su cuantificación y ubicación.

\section{MATERIALES Y MÉTODOS}

El área de influencia de la Denominación de Origen del Tequila (DOT), es de carácter interestatal y las superficies ocupadas por agave se distribuyen de manera dispersa aunque en ciertas localidades tiene una mayor concentración (Valenzuela, 1994; González et al., 2007).

Esta investigación se llevó a cabo en los municipios de El Arenal, Amatitlán y Tequila, zona tradicional del cultivo de agave y producción de tequila. El área de trabajo se distribuye dentro de las coordenada extremas noroeste: $21^{\circ} 00^{\prime} 10.7^{\prime \prime} \mathrm{N}, 103^{\circ} 54^{\prime} 10.3^{\prime \prime} \mathrm{O}$ y sureste: $20^{\circ} 40^{\prime} 17.1^{\prime \prime} \mathrm{N}, 103^{\circ} 33^{\prime} 40.6^{\prime \prime} \mathrm{O}$, para el sistema de referencia WGS84. En este polígono es donde se localiza la mayor concentración de predios ocupados con agave, para estos municipios. Presenta una fuerte influencia volcánica (Volcán de Tequila), se incluye en la provincia fisiográfica conocida como Eje Transversal Neovolcánico (SPP, 1981), que determina en gran medida las características de superficie y las condiciones de suelo, principalmente pedregosidad y relieve ondulado que orientan el uso hacia el cultivo del agave (Demant, 1978).
Para el reconocimiento por percepción remota de factores que restringen el desarrollo del cultivo del agave, se utilizó la imagen LANDSAT 5 del 2 de abril de 2011, adquirida durante la estación seca enero-junio, que permite un mejor contraste entre los predios con agave y otras cubiertas.

El satélite LANDSAT 5 está equipado con el sensor denominado Mapeador Temático (Thematic Mapper TM) que captura la radiación proveniente de la superficie terrestre en siete bandas espectrales, cada una para registrar características de objetos en la superficie: suelos, vegetación, agua, etc. (López y Caselles, 1991).

En el aspecto cartográfico, se utilizaron archivos imágenes de cartas topográficas a escala 1:50000, editadas por el Instituto Nacional de Estadística Geografía e Informática (INEGI) que abarcan el área de proyecto; estas cartas fueron F13D54, Tequila; F13D55, Tesistán; F13D64, Tala y F13D65, Guadalajara oeste, así como, archivos vectoriales para estas mismas cartas. Los archivos de imagen topográfica se georreferenciaron y unieron en mosaico mediante la herramienta Geocoding Wizard y Mosaiking (ER Mapper, 1999).

Como un recurso abierto de las tecnologías de la información geográfica, se ha hecho uso del sitio Google Earth, tanto para obtener escenas de interés como para ubicar predios con coordenadas geográficas en datum WGS84, obtenidas en campo. Las imágenes que maneja Google Earth, para el área de estudio son imágenes de alta resolución que permiten hacer acercamientos a nivel de líneas de agave.

Para la ubicación de los predios en campo se usó un navegador satelital marca Garmin Etrex de 12 canales. Este navegador ofrece posiciones con un rango de precisión de hasta $4 \mathrm{~m}$, que para fines de ubicar y registrar el predio que se visita para la obtención de datos, es suficiente. Para el procesamiento de datos de la imagen, se usó una computadora y el software ER MAPPER 6 (ER Mapper, 1999).

Actualmente, la localización geográfica de cualquier punto sobre la superficie de la tierra se hace con base en sistemas de referencia. Estos son modelos que establecen la relación entre la forma de la Tierra y sus dimensiones. El primero de estos modelos utilizado para México por la Comisión de Estudios del Territorio Nacional (CETENAL) creada en 1968 y actualmente Instituto Nacional de Estadística, Geografía e Informática, fue el sistema de referencia conocido 
como North American Datum, 1927 (NAD27) (Hansen, 2005).

Se generó el mapa base para localizar cualquier punto o rasgo sobre la superficie del área de proyecto y a la vez referir a este mapa base los materiales de imágenes que se fueran obteniendo. Esto se hizo georreferenciando las cartas topográficas de INEGI a escala 1:50000 del área de estudio, a su sistema de referencia inicial NAD27. Posteriormente, se procesaron estos materiales para unirlos en mosaico y por último hacer la reproyección del mosaico obtenido al sistema de referencia WGS84. Estos procesos se hicieron según el Manual de Trabajo de ER MAPPER 6 (ER Mapper, 1999).

Las bandas de la imagen se procesaron para su calibración radiométrica, corrección atmosférica, georreferenciación. Esto se realizó para toda la escena 29/46 (path/route) en su conjunto, banda por banda y ya corregida por estos conceptos se le realizó un recorte para dejar solo el área de estudio.

Se generó el compuesto a color usando la Banda 4 (infrarrojo cercano), Banda 5 (infrarrojo medio) y la Banda 6 (infrarrojo térmico) asignando canal rojo, verde y azul, respectivamente. Este manejo de banda dio como salida una imagen en compuesto a color (falso color), que fue la que mejor separó las cubiertas o usos del suelo y que a su vez ayudó a diferenciar el cultivo del agave azul de otras cubiertas y de sí mismo, incluyendo edades y estados de desarrollo (Flores et al., 2008).

Los sitios en los que los patrones de color sugirieron cambios en la cubierta se marcaron con puntos para reconocimiento en campo, los que fueron examinados para la captura de información. La información obtenida hace referencia al estado del cultivo o cubierta y condiciones de sitio, registrándose en fotografías, audio y video. El trabajo de campo se realizó con apoyo del Consejo Regulador del Tequila (CRT) y su supervisor de campo para la zona. Se trabajó durante los años 2011, 2012 y 2013.

La imagen del LANDSAT 5, está definida por su resolución espacial ( $30 \mathrm{~m}$ el tamaño del pixel para las bandas del visible e infrarrojo y $120 \mathrm{~m}$ para la banda térmica), resolución espectral (siete bandas del espectro electromagnético), resolución radiométrica (imagen de 8 bits, el valor del pixel tiene un rango de 0 a 255) y su resolución temporal (lapso de revisita de 16 días).
La calibración radiométrica (Chander et al., 2009) se realizó banda por banda utilizando el software ENVI 4.7. El número digital o nivel digital (ND) a través del proceso de calibración radiométrica es transformado a cantidad de energía (radianza) y ésta a valor de reflectancia (Chander et al., 2009).

El siguiente proceso en el tratamiento de la imagen fue el de corrección atmosférica. La energía recibida por el sensor es la suma de la energía reflejada por los objetos en la superficie y la energía dispersada y reflejada por la atmósfera. Fue necesario corregir estos efectos de la atmósfera para dejar sólo los correspondientes a los objetos en la superficie.

El método empleado fue el de pixel oscuro; mínimo del histograma. Este se basa en que la reflectividad en el océano (cuerpos de agua) es prácticamente nula, toda la energía recibida desde los pixeles del océano proviene de la atmósfera; estos pixeles del océano coincidirían con los valores mínimos del histograma de las imágenes (Chávez, 1988).

De las estadísticas de cada banda de la imagen se obtuvo el valor mínimo del pixel, diferente de cero. Ese valor mínimo corresponde al cuerpo de agua que absorbe la energía incidente y la que llega al sensor corresponde a la reflejada por la atmósfera.

Este valor mínimo se restó a los valores de los pixeles de toda la banda y por cada banda, obteniendo una nueva imagen con las siete bandas corregidas por el efecto de la atmósfera. Respecto a la georreferenciación, la imagen ya se obtiene corregida geométricamente (nivel 1). La corrección geométrica consistió en la verificación de este proceso. Para este caso se comparó la imagen de trabajo, con imágenes vectoriales editadas por INEGI; cartas F13D54 Tequila y F14D55 Guadalajara oeste a escala 1:50 000 coincidiendo rasgos vectoriales con rasgos de la imagen de manera fiel.

Con estos tres procesos asegurados: calibración radiométrica, corrección atmosférica y rectificación geométrica, el siguiente proceso fue el recorte del área de estudio. Este consistió en tres etapas: 1) Hacer compilación de las 7 bandas de LANDSAT agrupadas en un sólo archivo (Layer Stacking), para tener la escena completa de la imagen en un solo archivo. 2) Obtener una subescena que incluye el área de interés. Esta subescena se distribuye en cuadrante noroeste entre las coordenadas extremas noroeste: $21^{\circ} 00^{\prime} 10.7^{\prime \prime} \mathrm{N}$, $103^{\circ} 54^{\prime} 10.3$ " O y sureste: $20^{\circ} 40^{\prime} 17.1^{\prime \prime} \mathrm{N}, 103^{\circ} 33^{\prime}$ 
40.6” O. 3) Trazar el polígono que delimita el área de estudio, y su conversión a REGIÓN para segregarlo del resto y dejarlo como área de estudio. Estos procesos se realizaron con las herramientas del programa ER MAPPER 6 (ER Mapper, 1999).

La interpretación digital de la imagen se hizo sobre el área de estudio segregada y considerando las 7 bandas de la imagen. El método utilizado fue el de Clasificación Supervisada (ER Mapper 6, 1999) que opera con campos de entrenamiento (muestras) de datos reales para aplicarlos a los datos de toda la imagen a clasificar. En la formación de grupos o clases, éstos deberán corresponder a los diferentes tipos de usos o cubiertas asignados en los campos de entrenamiento.

Se utilizaron cuatro campos de entrenamiento para cada una de las cubiertas identificadas: bosque de pino, bosque de encino, matorral, etc. y, por supuesto, agave en diferentes edades y estados de producción.

En este proceso se utilizó la opción de máxima probabilidad. Se obtuvo un mapa de clases en base a los tipos de uso o cubiertas indicadas en los campos de entrenamiento, así como, el listado de las estadísticas para cada clase de cubierta de donde se obtiene la superficie total del área de proyecto y la superficie de los diferentes usos de suelo o cubierta. Para la evaluación de la precisión de esta información se trabajó una matriz de error (Conglaton, 1991; Jensen, 2005), utilizando puntos de distribución aleatoria y comparándolos con la verdad de tierra.

Adicionalmente se consideró conveniente mostrar los valores de reflectancia para cada una de las cubiertas o uso del suelo reportados por el proceso de clasificación supervisada para la banda 4 (infrarrojo cercano); así mismo, se muestran los valores del índice de vegetación (NDVI), para las mimas cubiertas.

\section{RESULTADOS Y DISCUSIÓN}

A las restricciones identificadas por las observaciones de campo, los patrones de color reflejados en la imagen, y el resultado de la clasificación supervisada, se les agrupó en tres clases:

1. Restricciones relacionadas a la economía del productor; restricciones tipo 1.

2. Restricciones debidas a la sanidad del cultivo; restricciones tipo 2 .

3. Restricciones relacionadas con el exceso de humedad en suelos planos; restricciones tipo 3.

En el compuesto a color de la imagen de trabajo, y con un contraste de 0.98 , los predios con Restricciones Tipo 1 que son los desatendidos, los asociados con maíz o los invadidos por maleza, presentan tonos claros con variantes tenues a verde, azul, o gris rosáceo que en el sistema RGB corresponden a las mezclas 181, 244, 253 para el azul tenue y 190,143, 179 para tonos gris rosáceo. No debe ignorarse que estas condiciones del cultivo pueden confundirse con otras cubiertas como pastizales o vegetación arbustiva debido a que el agave desatendido se comporta como una especie arbustiva más. Por otro lado, la interpretación se hace sobre una imagen adquirida en periodo seco en el que la actividad fotosintética solo se presenta en especies forestales, cultivos de riego, agave y vegetación acuática. (Pimienta et al., 2006).

En el caso de predios de agave afectados por alguna enfermedad, las hojas medias y cogollo tienden a secarse, lo que se observa principalmente en predios mayores a 4 años y en la imagen se registran con tonalidades tendientes al naranja y al azul púrpura, que en el sistema RGB corresponden a las mezclas 250 , 196, 84 para el tono naranja y 117, 50, 190 para el tono azul púrpura. Igualmente, estos tonos se pueden confundir con pastos, céspedes o caña de azúcar y con agave de 2 ó 3 años, respectivamente; la discriminación corresponderá al responsable técnico del área.

Para el grupo 3, o restricciones tipo 3, en el compuesto a color se manifiesta en un azul-púrpura; advirtiéndose que para este caso pudiera confundirse con agaves de 2 a 3 años de edad.

Este análisis visual, en primera instancia, permite focalizar los predios con problemas, así como los predios con buen desarrollo y estimar cualitativamente una expectativa de rendimiento o bien dirigir acciones a predios con restricciones susceptibles de ser beneficiados.

Del proceso de clasificación supervisada, se obtuvo un mapa temático de distribución de las cubiertas clasificadas como agave y no agave (Figura 1). Así mismo, se generó otro mapa que muestra las restricciones en clases, donde el color azul representa a las restricciones tipo 1 asociadas con manejo; el naranja las restricciones tipo 2 asociadas a la sanidad de la planta, y en rojo, restricciones tipo 3 en donde el deterioro por desecación de la planta está asociado a exceso de humedad en terrenos planos (Figura 2).

La Figura 3 representa el mapa temático de restricciones sobre el mosaico de carta topográfica a escala 1:50000; este mapa es de especial interés ya que 
Distribución: Agave-No agave

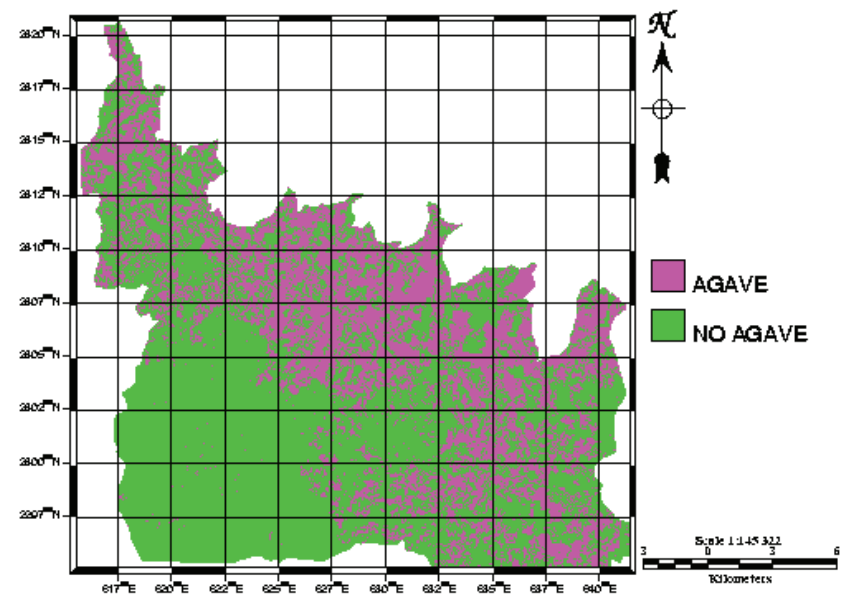

Figura 1. Resultado de la clasificación supervisada que muestra la distribución de superficies ocupadas por agave contra otros tipos de usos del suelo (no agave).

los predios con restricciones son ubicables en campo.

Se obtuvo la superficie en hectáreas por uso del suelo o cubierta terrestre, por medio de la clasificación supervisada (Cuadro 1). El proceso reportó para las Restricciones Tipo 1 asociadas al manejo del cultivo, 4601 ha; para las Restricciones Tipo 2 asociadas a la sanidad del cultivo, 729 ha y para Restricciones Tipo 3 asociadas a excesos de humedad en terrenos planos, 630 ha que en total suman 5962 ha que representan el $45 \%$ del total ocupado por agave en la zona de estudio.

Distribución: Agave con restricciones

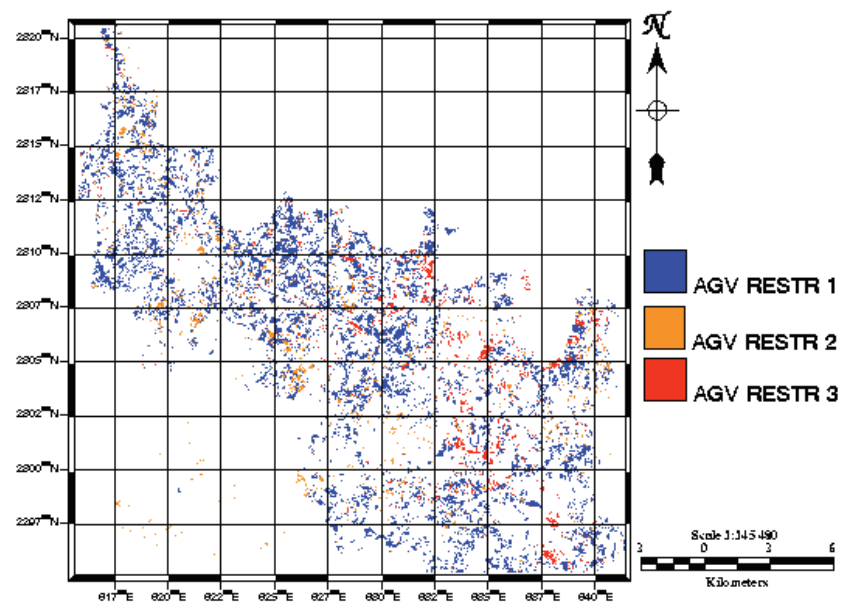

Figura 2. Resultado de la clasificación supervisada que muestra la distribución de las superficies con restricciones en el cultivo. Restricción tipo 1 = aspectos económicos; Restricción tipo 2 = plagas y enfermedades; Restricción tipo $3=$ efectos por exceso de humedad del suelo.
Distribución: Agave con restricciones

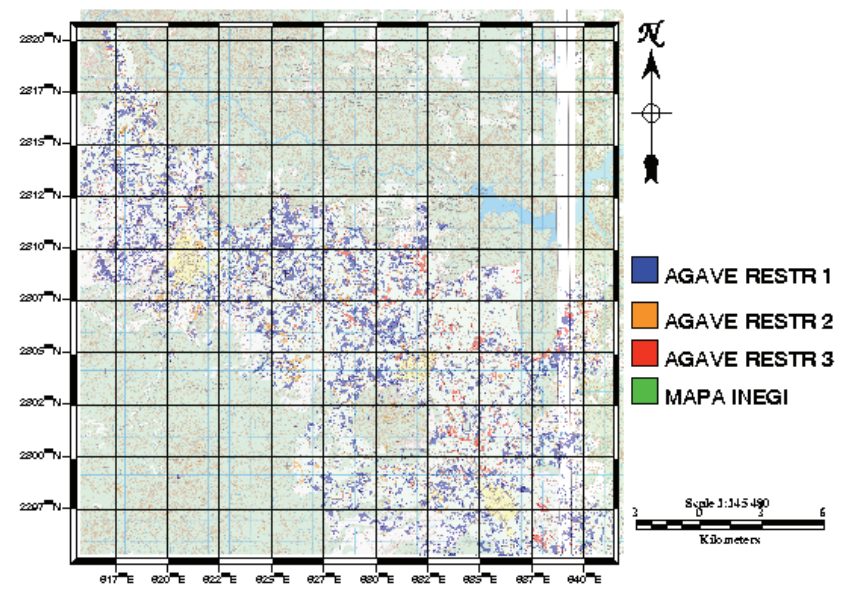

Figura 3. Mapa de clases con restricciones y su base cartográfica. Restricción tipo 1 = aspectos económicos; Restricción tipo 2 = plagas y enfermedades; Restricción tipo $3=$ efectos por exceso de humedad del suelo.

Uvalle-Bueno et al. (2006) mencionan que en estudio fitosanitario del CRT de 1997, al menos el 23\% del inventario del agave tequilero tenía algún grado de enfermedad, valor que prácticamente se duplicó en 2005. Este dato comparable con lo obtenido en la presente investigación (año 2011).

Los datos de superficie acorde con el uso de suelo (Cuadro 1), junto con el mapa de clases donde se muestra la distribución del agave con restricciones en su desarrollo, permitirán hacer evaluaciones sobre lo que se espera en rendimiento del cultivo y tomar las acciones que esto sugiera.

La información publicada sobre el cultivo del agave azul y su relación con imágenes de satélite, ya sea para fines de identificación, ubicación, monitoreo o estado de desarrollo, es escasa o prácticamente nula. Las experiencias son de la segunda mitad de los años 90's y principios de los años del S. XXI, no documentadas. No obstante el uso de imágenes satelitales para el estudio de recursos naturales como vegetación, suelos, agua y minerales si está documentada (Valladares, 2004; Lencinas y Mohr-Bell, 2007; Manjarrez-Domínguez et al., 2007), utilizando imágenes en compuesto a color, procesos de clasificación no supervisada y supervisada e índices de desarrollo vegetal, así como procesos estadísticos. Estos trabajos han mostrado su utilidad para separar cubiertas o usos del suelo que son diferentes entre sí en la realidad. 
Cuadro 1. Superficies obtenidas de la clasificación supervisada para diferentes usos del suelo.

\begin{tabular}{|c|c|c|c|c|c|}
\hline Uso del suelo & Superficie & Superficie/agave & Suprtficie/sin agave & $\begin{array}{l}\text { Superficie/agave } \\
\text { restricciones }\end{array}$ & $\begin{array}{l}\text { Superficie/agave } \\
\text { restricciones }\end{array}$ \\
\hline Cubiertas superficiales & $\ldots \ldots$ & $\ldots \ldots$ & - ha $\ldots \ldots$ & $\ldots \ldots$ & $\%$ \\
\hline Agave restricciones 1 & 4601.74 & & & & \\
\hline Agave restricciones 2 & 729.81 & & & & \\
\hline Agave restricciones 3 & 630.99 & & & 5962.59 & 45.49 \\
\hline Agave 2010 & 593.19 & & & & \\
\hline Agave 2009 & 2079.99 & & & & \\
\hline Agave 2008 & 907.56 & & & & \\
\hline Agave 2007 & 232.92 & & & & \\
\hline Agave 2006 & 695.61 & & & & \\
\hline Agave 2005 & 864.81 & & & & \\
\hline Agave 2004 & 1769.76 & 13106.43 & & & \\
\hline Redrojo & 3797.64 & & & & \\
\hline Residuos de cultivo & 770.67 & & & & \\
\hline Barbecho & 987.84 & & & & \\
\hline Vegatación secundaria & 3928.05 & & & & \\
\hline Vegetación quemada & 1544.31 & & & & \\
\hline Zona urbana & 1536.57 & & & & \\
\hline Matorral & 1606.95 & & & & \\
\hline Riego & 693.09 & & & & \\
\hline Bosque de pino & 5536.08 & & & & \\
\hline Bosque de encino & 4153.14 & & 23895.09 & & \\
\hline Total & 35464.95 & & & & \\
\hline
\end{tabular}

Restricción tipo 1 = aspectos económicos; Restricción tipo 2 = plagas y enfermedades; Restricción tipo 3 = efectos por exceso de humedad del suelo.

Esta diferenciación de cubiertas fue congruente con el mapa de clases obtenido por la clasificación supervisada (Figura 2), logrando separar superficies ocupadas con agave con problemas de desarrollo, al contrastar el mapa de clase con el compuesto a color. La evaluación de la precisión, a través del análisis de la matriz de error (Conglaton, 1991; Jensen, 2005) se muestra en el Cuadro 2, cuya precisión general resultó del $73 \%$.

De este análisis, para las clases de agave con restricciones se concluye que el resultado de la clasificación supervisada es de utilidad, considerando que los errores o confusiones se dan entre clases cuyo aspecto en campo son similares. Cabe señalar que prácticamente no se presenta confusión con ninguna de las otras clases de agave en diferentes edades de desarrollo, salvo la clase Agave Restricciones 3 que tiende a reflejar la misma matiz de color que la clase Agave 2008 debido a la influencia del suelo.
Dadas las características del cultivo, objeto de esta investigación, su manejo y desarrollo, es de esperarse que en el procesamiento de la imagen siempre haya un riesgo de confusión; así se apreció en la presente investigación, pero esta confusión puede ser aminorada con la interpretación del personal a cargo del manejo de esta tecnología y con conocimiento del hábito del cultivo. No obstante, el resultado es una herramienta básica para verificar su corroboración en campo y establecer criterios de decisión sobre el manejo del cultivo según las condiciones y restricciones encontradas.

El Cuadro 3 muestra los valores de reflectancia para cada una de las cubiertas reportadas. Se presentan los valores de la Banda 4 (infrarrojo cercano) por ser la que mejor responde a la vegetación (Jackson y Huete, 1991), asimismo, se incluyen los valores de NDVI; también adimensionales, obtenidos en el proceso de datos de la imagen de trabajo con el propósito de 
Cuadro 2. Resumen de la matriz de error: clasificación supervisada.

\begin{tabular}{lclc}
\hline \multicolumn{4}{c}{ Precisión general: 73\% } \\
\hline $\begin{array}{l}\text { Precisión del productor } \\
\text { (clasificación supervisada) }\end{array}$ & $\%$ & $\begin{array}{l}\text { Precisión del usuario } \\
\text { (verdad terreno) }\end{array}$ & $\%$ \\
\hline Agave restricciones 1 & 90 & Agave restricciones 1 & 91 \\
Agave restricciones 2 & 0 & Agave restricciones 2 & 0 \\
Agave restricciones 3 & 100 & Agave restricciones 3 & 33 \\
Agave 2010 & Na & Agave 2010 & Na \\
Agave 2009 & 50 & Agave 2009 & 100 \\
Agave 2008 & 85 & Agave 2008 & 73 \\
Agave 2007 & 57 & Agave 2007 & 80 \\
Agave 2006 & 64 & Agave 2006 & 100 \\
Agave 2005 & 20 & Agave 2005 & 50 \\
Agave 2004 & 100 & Agave 2004 & 50 \\
Redrojo & 86 & Redrojo & 100 \\
Barbecho & $\mathrm{Na}$ & Barbecho & $\mathrm{Na}$ \\
Vegetación secundaria & 50 & Vegetación secundaria & 50 \\
Matorral & 100 & Matorral & 60 \\
\hline
\end{tabular}

$\overline{\text { Restricción tipo } 1 \text { = aspectos económicos; Restricción tipo } 2=\text { plagas y }}$ enfermedades; Restricción tipo 3 = efectos por exceso de humedad del suelo. mostrar la respuesta, especialmente de las plantas de agave al estímulo de la energía incidente.

La vegetación de agave de 2004 a 2007 varió en el rango de 0.241 a 0.294 . Para esta banda, B4, en este rango ocurren el agave con restricciones 1 , el agave con restricciones 2 , el bosque de pino y la vegetación secundaria. Las cubiertas de agave 2008, 2009 y 2010 presentaron un rango de 0.142 a 0.195 , menor a las cubiertas de agave estudiadas, lo cual se explica por ser plantas menores a 3 años. El valor más alto lo reporta la vegetación bajo riego con 0.434 . Con respecto al índice de vegetación (NDVI), los valores que comparativamente presentan un valor más alto de 0.301 y 0.357 correspondieron al agave 2008 y 2007 respectivamente, esto para las edades de 3 a 4 años. En el resto de cubiertas, la vegetación de riego con 0.769 y el bosque de pino con 0.609 son las que reportaron los valores más altos de NDVI, lo cual se debe a que la vegetación de tipo forestal cubre totalmente el suelo y la vegetación bajo riego se mantiene activa en la época de sequía (noviembre - junio).

Cuadro 3. Valores de reflectancia para la Banda 4 y valores de NDVI por uso del suelo o cubiertas registradas.

\begin{tabular}{|c|c|c|c|c|c|c|c|c|}
\hline \multirow{2}{*}{$\begin{array}{l}\text { Uso o cubierta } \\
\text { Agave restricciones } 1\end{array}$} & \multicolumn{3}{|c|}{ Latitud } & \multicolumn{3}{|c|}{ Longitud } & \multirow{2}{*}{$\frac{\text { Reflc._B4 }}{0.248}$} & \multirow{2}{*}{$\frac{\text { NDVI }}{0.261}$} \\
\hline & 20 & 50 & 52.39 & 103 & 44 & 16.51 & & \\
\hline Agave restricciones 2 & 20 & 50 & 47.9 & 103 & 47 & 34.36 & 0.282 & 0.256 \\
\hline Agave restricciones 3 & 20 & 53 & 3.56 & 103 & 45 & 58.19 & 0.192 & 0.235 \\
\hline AGV_2010 & 20 & 50 & 47.77 & 103 & 46 & 30.05 & 0.142 & 0.191 \\
\hline AGV_2009 & 20 & 51 & 13.4 & 103 & 41 & 21.59 & 0.182 & 0.202 \\
\hline AGV_2008 & 20 & 58 & 17.96 & 103 & 52 & 18.62 & 0.195 & 0.301 \\
\hline AGV_2007 & 20 & 51 & 44.92 & 103 & 47 & 59.77 & 0.294 & 0.357 \\
\hline AGV_2006 & 20 & 53 & 1.09 & 103 & 49 & 28.3 & 0.288 & 0.25 \\
\hline AGV_2005 & 20 & 55 & 58.95 & 103 & 51 & 54.21 & 0.264 & 0.278 \\
\hline AGV_2004 & 20 & 52 & 12.03 & 103 & 43 & 51.38 & 0.241 & 0.238 \\
\hline Redrojo & 20 & 58 & 46.25 & 103 & 52 & 19.28 & 0.236 & 0.187 \\
\hline Residuos de cultivo & 20 & 52 & 4.41 & 103 & 45 & 56.23 & 0.378 & 0.189 \\
\hline Barbecho & 20 & 52 & 10.32 & 103 & 48 & 14.95 & 0.171 & 0.138 \\
\hline Vegetación secundaria & 20 & 56 & 44.73 & 103 & 52 & 22.98 & 0.248 & 0.204 \\
\hline Vegetación quemada & 20 & 54 & 20.98 & 103 & 50 & 18.36 & 0.099 & 0.111 \\
\hline Zona urbana & 20 & 52 & 54.49 & 103 & 50 & 12.05 & 0.245 & 0.176 \\
\hline Matorral & 20 & 50 & 26.58 & 103 & 49 & 13.78 & 0.238 & 0.26 \\
\hline Riego & 20 & 57 & 57.65 & 103 & 51 & 46.77 & 0.434 & 0.769 \\
\hline Bosque de pino & 20 & 46 & 38.59 & 103 & 50 & 4.11 & 0.276 & 0.609 \\
\hline Bosque de encino & 20 & 45 & 52.6 & 103 & 49 & 20.45 & 0.201 & 0.297 \\
\hline
\end{tabular}




\section{CONCLUSIONES}

El uso de imágenes LANDSAT por su resolución espectral y radiométrica es aceptable para el estudio del cultivo del agave azul según lo observado en campo y lo expresado por el procesamiento de la imagen. El proceso permite la identificación puntual del cultivo y su condición de desarrollo, lo que ayuda a focalizar la toma de decisiones.

En el presente estudio el $45 \%$ de la superficie ocupada con agave reflejó problemas en su desarrollo; esto representa, aproximadamente 5962 ha, con una confiablidad obtenida de la matriz de error del $73 \%$. Este hallazgo justifica la aplicación de la metodología usada en acciones de seguimiento del cultivo en su desarrollo.

En la presente investigación la Banda 4 y el Índice de Vegetación del agave con restricciones reporta valores de 0.192 a 0.282 y de 0.235 a 0.261 , respectivamente. Por la escasez de información sobre el tema y los resultados reportados, este trabajo representa un esfuerzo que retoma acción realizadas en el pasado reciente sobre esta temática y permite abrir una etapa de trabajos que amplíen el estudio del agave con esta herramienta metodológica.

\section{LITERATURA CITADA}

Bautista-Justo, M., L. García-Oropeza, J. E. Barboza-Corona, y L. A. Parra-Negrete. 2001. El Agave tequilana Weber y la producción de tequila. Acta Universitaria 11: 26-34.

Bozinovic, F. y M. Canals. 2009. Fisiología ecológica de mamíferos: Compromisos y restricciones en el uso de la energía. pp. 315334. In: A. Muñoz-Pedreros y J. Yáñez Valenzuela (eds.). Mamíferos de Chile. CEA Ediciones. Valdivia, Chile.

Conglaton, R. G. 1991. A review of assessing the accuracy of classifications of remotel y sensed data. Remote Sens. Environ. 37: 35-46.

CRT (Consejo Regulador del Tequila). 2004. "Tequila de Origen" "El Agave Azul A Través de la Imagen de Satélite" - "Blue Agave Through a SatelliteImage". Guadalajara, Jal. http:// crtequila.blogspot.mx/2007/01/el-agave.html. (Consulta: octubre 22, 2015).

Chander, G., B. L. Markham, and D. L. Helder. 2009. Summary of current radiometric calibration coefficients for landsat MSS, TM, ETM+, and EO-1 ALI sensors. Remote Sens. Environ. 113: 893-903.

Chávez Jr., P. S. 1988. An improved dark-objet subtraction thecnique for atmospheric scattering correction for multispectral data. Remote Sens. Environ. 24: 459-470.

Chuvieco, E. 1995. Fundamentos de teledetección espacial. Ed. Rialp. Madrid, España.
Demant, A. 1978. Características del eje neovolcánico transmexicano y sus problemas de interpretación. Rev. Mex. Cienc. Geol. 2: 172-187.

ER Mapper (Earth Resource Mapping). 1999. ER Mapper 6. Level one training workbook for land information aplications. San Diego, CA, USA.

Flores G., J., R. Reich, E. Talavera Zúñiga, and C. Aguirre Bravo. 2008. Using remote sensing to support different approaches to identify agave (Agave tequilana Weber) crops. pp. 941-948. In: International Society for Photogrammetry and Remote Sensing (ed.). The International Archives of the Photogrammetry, Remote Sensing and Spatial Information Sciences. Vol. 37. Part B8. Beijing, China. ISSN: 1682-1750.

González, I. A. 2004. Introducción a la percepción remota. pp. 455481. In: F. Bautista Z., H. Delfín G., J. L. Palacio P. y M. C. Delgado C. (eds.). Técnicas de muestreo para manejadores de recursos naturales. Universidad Nacional Autónoma de México. Universidad Autónoma de Yucatán. Consejo Nacional de Ciencia y Tecnología. Instituto Nacional de Ecología. México, D. F. ISBN 970-32-1778-8.

González H., H., J. I. Del Real L. y J. F. Solís A. 2007. Capitulo I. Introducción. pp. 1-23. In: H. González H., J. I. Del Real L. y J. F. Solís A. (eds.). Manejo de plagas del agave tequilero. Colegio de Postgraduados y Tequila Sauza S.A. de C.V. Zapopan, Jalisco, México.

Hansen A., F. A. 2005. Geodesy as a fundamental data set in the mexican SDI (Idemex). From Pharaons to Geoinformatics. FIG Working Week 2005 and GSDI-8 Cairo, Egypt April 16-21, 2005. (https://www.fig.net/resources/proceedings/fig proceedings/cairo/papers/ts_13/ts 13 _03_hansen.pdf). (consulta: enero 28, 2015).

Jackson, R. D. and A. R. Huete. 1991. Interpreting vegetation indices. Prev. Vet. Med. 11: 185-200.

Jensen, J. R. 2005. Introductory digital image processing: A remote sensing perspective. Prentice-Hall. Englewood Cliffs, NJ, USA.

Lencinas, J. D. y D. Mohr-Bell. 2007. Estimación de clases de edad de plantaciones de la provincia de corrientes, Argentina, con base a datos satelitales Landsat. Bosque 28: 106-118.

Lillesand, T. and R. W. Kieffer. 1987. Remote sensing and image interpretation. Wiley and Sons. Chichester, England.

López García, M. J. y V. Casselles. 1991 Introducción a la teledetección. pp. 19-49. In: S. Gandia S. y J. Meliá (eds.). La teledetección en el seguimiento de los fenómenos naturales: Recursos renovables, agicultura. Universitat de Valencia. Valencia, España.

López, J. F., S. Fernández H. y C. Lozada R. 2008. Análisis factorial con componentes principales para interpretación de imágenes satelitales "LANDSAT TM 7" aplicado en una ventana del departamento de Risaralda. Sci. Tech. 14 38: pp. 241-246.

Manjarrez-Domínguez, C., C. Pinedo-Álvarez, C. E. VélezSánchez Verín y A. Pinedo-Álvarez. 2007. Separabilidad espectral de cultivos agrícolas con imágenes LANDSAT TM. Tecnociencia. 1: 48-56.

Pimienta B., E., J. Zañudo H., J. García G. y P. S. Nobel. 2006. Ecofisiología del Agave Azul. Universidad de Guadalajara. Centro Universitario de Ciencias Biológicas y Agropecuarias. Ed. Pandora. Zapopan, Jal. México. 
Smith, R. B. 2012. Introduction to remote sensing of Environment (RSE). (http://www.microimages.com/ documentation/Tutorials/introrse.pdf) (Consulta: enero 28, 2015).

SPP (Secretaria de Programación y Presupuesto). 1981. Síntesis geográfica del estado de Jalisco. Coordinación General de los Servicios Nacionales de Estadística, Geografía e Informática. México, D. F. ISBN968-809-187-1.

Uvalle-Bueno, J. X., C. Vélez-Gutiérrez, A. Ramírez-Figueroa, R. E. Carrillo-González, A. Balcazar-Arizaga y L. R. ValenzuelaBuitimea. 2006. Enfermedades fitopatológicas del agave tequilero (Agave tequilana Weber var. Azul). pp. 44-64. In: J. S. Bernal, A. Orozco H., J. I. Del Real y H. González H. (eds.). Estado actual del manejo de plagas y enfermedades del agave tequilero: Memorias del simposio prioridades fitosanitarias actuales en el cultivo del Agave tequilana Weber var. Azul. XXIX Congreso Nacional de Control Biológico. Colegio de Postgraduados y Tequila Sauza. Manzanillo, Colima, México. ISBN: 9688935285.

Valenzuela Z., A. G. 1994. El agave tequilero, su cultivo e industria. Litteris. Guadalajara, México.

Valladares, F., I. Aranda y D. Sánchez Gómez. 2004. La luz como factor ecológico y evolutivo para las plantas y su interacción con el agua. pp. 335-369. In: F. Valladares (ed.). Ecología del bosque mediterráneo en un mundo cambiante. Ministerio de Medio Ambiente. EGRAF. Madrid, España.

Vega G., A., J. López-García y L. L. Manzo D. 2008. Análisis espectral y visual de vegetación y uso del suelo con imágenes LANDSAT TM+ con apoyo de fotografías aéreas digitales en el corredor biológico Chichinautzin, Morelos, México. Invest. Geog. 67: 59-75. 